\title{
Interactive u-learning Model for Student Directed Learning
}

\author{
Hyejin Kim \\ Institute of School Safety Research, Sungshin Women's University, Bomun-ro \\ 34da-gil, Seongbuk-gu, Seoul, South Korea \\ email: hyejinaa@hanmail.net
}

\begin{abstract}
The emerging trends of technology very often have been a driving force for innovation in education. The advent of open education resources, social networking technologies, new pedagogies for online and blended learning, continuous development of ubiquitous computing technologies and its applications have brought about a revolution in the education, especially in learning environments. Although learning outside of the traditional classroom is an innovative teaching approach, the two main problems are the lack of proper learning strategies and the capacity to acquire knowledge on subjects interactively and effectively. This paper introduce interactive u-learning model for student directed learning which has different components, the learning communities, communication tools, knowledge building resource and sharing of learning resources.
\end{abstract}

Keywords: u-learning, interactive learning, student directed learning, open learning

\section{Introduction}

The use of digital media in education has led to an increase in the use of and reliance on interactive learning, which in turn has led to a revolution in the fundamental process of education. Learning is not limited to the classroom walls, but takes place (within a network of other co-learners, linked to one another, and also linked to the wealth of resources that are available on-line.

The u-learning community is an interactive social learning model designed in consideration of some factors that mainly influence the learning process of a learner member of the net generation. This model aims of accommodating learners in their learning style by providing adequate information at anytime and anywhere as they wish for it. Figure 1 depicts the flow of the development for the u-Learning system.

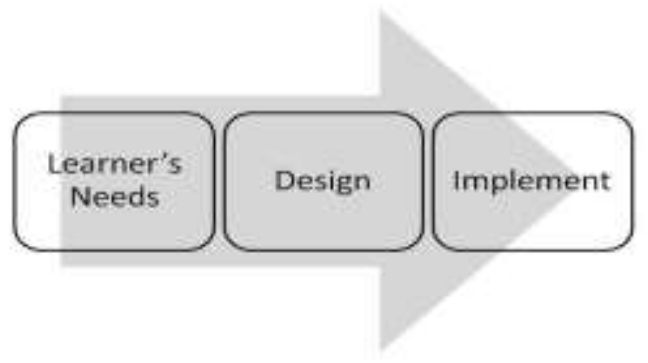

Figure 1. Depicts the Flow of the Development for the u-Learning System

The larger aim of student-directed teaching is to revolutionize education. Nascent in the progressive philosophy is a feeling that education has remained unchanged for far too long: since its inception, in fact, a century and a half ago. The global climate today differs vastly from that of 1850 . Arguably, the most important change in the last century has been the acceleration of the proliferation of information. The twentieth century has seen several 
importance advances in technology, including the invention of the transistor, the radio, the television, and finally, the Internet. Each of these inventions, evolutions, in turn, has accelerated the commonly understood notion of culture. And with each progressive acceleration, the strain on individuals, not just students, to make sense of the world increases. Although it affects everyone, it is most noticeable in children: ultimately, the institution of mass schooling has been unable to keep up with the changes dictated by the intense proliferation of knowledge. Students, thus is the claim of Student-Directed Teaching, are failed by the system, leaving them bored, apathetic and mundane.

\section{Background of the Study}

The background of the study includes the introduction of different learning strategies and technologies such as OpenLearning, Interactive Learning, Self-Directed Learning and Web Technologies use in u-learning.

\subsection{OpenLearning}

The OpenLearning stage keeps running as an electronic social learning and versatile application which has been developed from the beginning strong instructive establishments since its commencement. The objective is to give an exceptionally social learning condition in which understudies feel engaged, profound learning encounters are encouraged, understudies are inherently inspired, and enthusiastic groups of practice thrive through very much planned helpful encounters. This has been acknowledged with the most recent social innovation, and is intended for a worldwide, associated society. Moreover, OpenLearning is a trailblazer in the field, and stretches out existing instructive hypothesis to not just the plan thinking behind the mechanics of the stage, however by giving a platform to new scholastic instructive research with the capacity to consistently try different things with novel instructive mechanics for both instructors and technologists. [1].

OpenLearning uses a social media workflow to enable and encourage commenting and liking, meaning your course will foster a community of collaborative learners instead of individuals feeling lost in a sea of information.

It provides built-in galleries, wikis and blog pages to feature work and encourage collaboration and peer feedback, while always maintaining room for individuality. As an educator, you will be supported by a community of OpenLearning educators and be provided with training courses and ongoing support to ensure you have the tools to build the best experiences possible for your students.

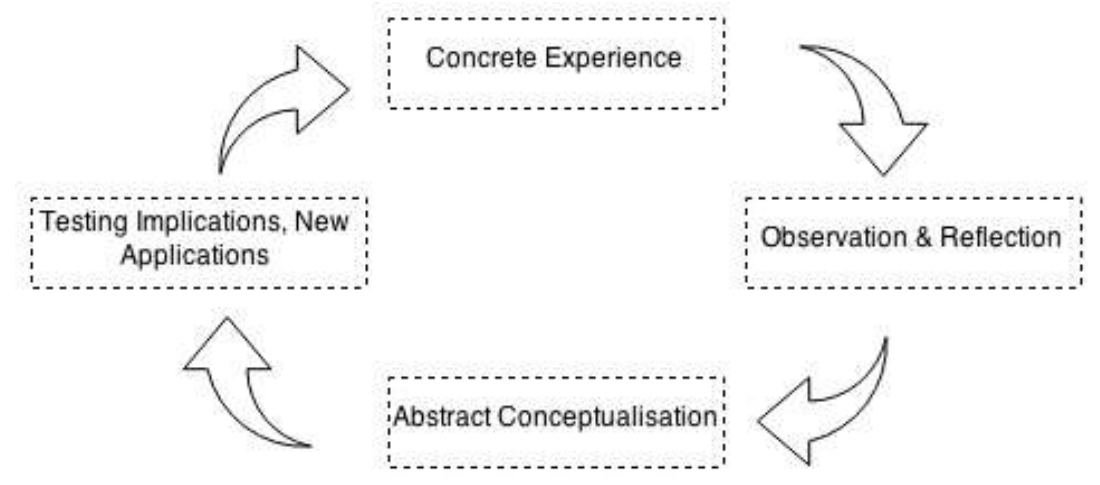

Figure 2. OpenLearning 
Universities in reality any grounds condition, can pick up a ton of significant worth from the location based service (LBS). There are a couple of qualities that render grounds as prime hotspots that empower wealthier WiFi-based LBS encounters [3].

\subsection{Interactive Learning}

Interactive Learning is a pedagogical approach that incorporates social networking and urban computing into course design and delivery. Interactive Learning has evolved out of the hyper-growth in the use of digital technology and virtual communication, particularly by students. Beginning around 2000, students entering institutes of higher education have expected that interactive learning will be an integral part of their education. The use of interactive technology in learning for these students is as natural as using a pencil and paper were to past generations.

Increasingly, students and teachers rely on each other to access sources of knowledge and share their information, expanding the general scope of the educational process to include not just instruction, but the expansion of knowledge. The role change from keeper of knowledge to facilitator of learning presents a challenge and an opportunity for educators to dramatically change the way their students learn. The boundaries between teacher and student have less meaning with interactive learning.

The socialization of education is evolving in the form of personalized digital media sources. Web logs, or blogs, enable students to express thoughts and ideas individually, while at the same time sharing them with the larger community. The pervasiveness of social networks like MySpace and Facebook connect millions of learners to a virtual community where information is exchanged laterally between and among students and teachers alike. This explosion of community is contributing to an expanding learning economy, where participants have unparalleled access to knowledge, both from teachers and other students. This set of technologies includes the use of wireless networks, smart phones and PDAs, search engines, and location-based media. Urban computing allows enhanced interactivity between people and their environment through the use of these technologies. For Interactive Learning, this means that students are able to assimilate knowledge specific to their location.

In order to be effective, learning institutions must see computers and associated technology as an essential part of the student. In other words, technology must be seen as cognitive prosthetics.[4] The core concept of distance education is that the real world becomes the learning environment; in this environment, the purpose of the instructor is to help facilitate the absorption of knowledge through both real-world and virtual learning experiences.[8] Historically, one of the obstacles to distance education is the lack of face to face contact. The use of technology as an integral part of course design has attempted to compensate in both synchronous and asynchronous settings.

For asynchronous content delivery, course designers use a variety of software suites that include various types of interactive elements. Programs such as WebCT, Knowledge Forum, FirstClass, Raptivity and Blackboard Learning System attempt to ameliorate the lack of contact with online discussion forums and bulletin boards.

It is essential that a knowledge-building community be allowed to develop in order for the learning to succeed. 


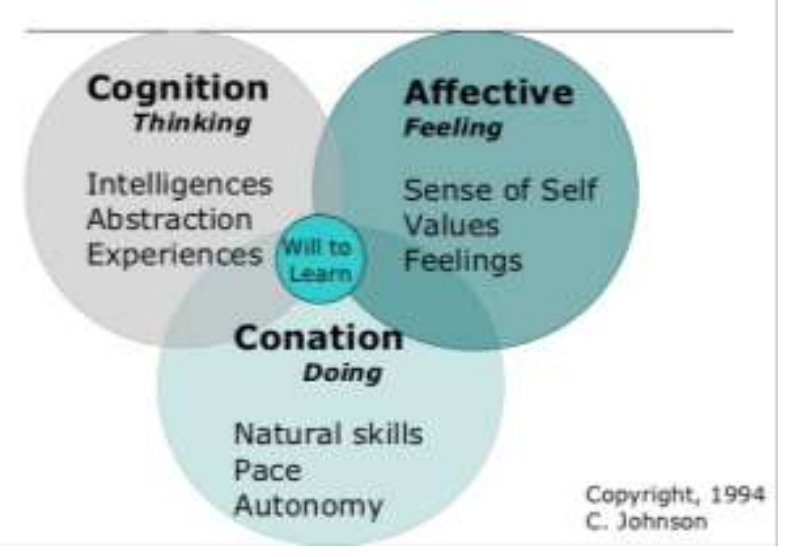

Figure 3. The Interactive Learning Model

\subsection{Self-Directed Learning}

The first principle is that programs should be congruent with a life of learning, the natural ways we learn and the unique methods by which each of us learns best. The basic assumption of SDL is that from birth to death we live lives of learning - learning to function then to live well and finally to make a difference. Learning is a natural process outlined both by the history of our species and our history as individuals. Our success depends upon the range, depth and quality of the learning we achieve. Each of us exhibits and develops these natural capacities in an individual way according to the talents we are endowed with, the experiences we encounter, the strengths we discover, the interests that begin to direct and motivate us and the patterns of learning that we develop. An SDL program should be congruent with these lifelong, natural and individual learning drives.

Student does - shares ideas, tries things out, evaluates ideas, listens to other ideas, is open to suggestions, shares responsibilities, respects other opinions.

Teacher's role - know when to stand back and when to be part of the team, keep the momentum going without dominating, model the social skills of group collaboration.

Teacher says - what other ideas does the group have, do we all agree on that, has anyone else got a good idea, who could help us with that, what else do we need to do. Just in time lectures on statistical analysis, data presentation, water quality parameters that affect fish. Problem assignments that build individual skills that can be applied to the project question. Teacher and TA are information sources, advisors, resources, but have never solved this specific problem and don't know the answer!

Individuals take initiative and responsibility for learning. Individuals select, manage, and assess their own learning activities. Motivation and volition are critical. Independence in setting goals and defining what is worthwhile to learn. Teachers provide scaffolding, mentoring, advising. Peers provide collaboration

This style is selected by students who make independent decisions, have a good understanding of how they learn and who are self-motivated. These students are beginning to individualize their learning and to compact the curriculum. They usually complete the unit several periods before the Command and Task students which results in their having Earned Time. This is time available to a student who has selected PeerPartner, Student-Teacher Contract or Self-Directed teaching style and who has completed the objectives of a unit in less time than allocated for the unit. In Earned Time, a student can work in an area of high interest, demonstrating high-level thinking and new learning. The choice is not to work, but rather to take part in a passion area directly related to the student's ability and interest. The passion area need not be related to the subject in which the student earned the time 


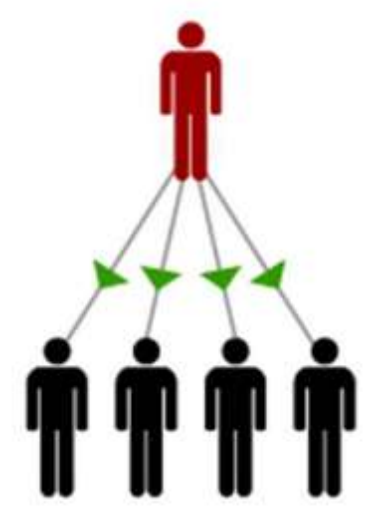

(a)

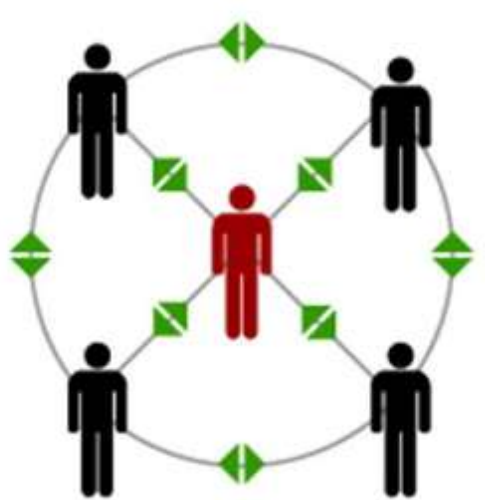

(b)

Figure 4. Teacher's Directed (a) vs. Students Directed Learning (b)

\subsection{Web Technologies Use in u-learning}

The Web has revolutionized almost every aspect of our lives, but the one that is underappreciated is learning. Thanks to the Web, access to educational content is more instantaneous and less expensive than ever before.

Even more significant is the Web's potential to empower lifelong, self-directed learning beyond the traditional classroom. This is particularly important in the today's knowledge-based economy, where most jobs have extensive and constantly evolving knowledge prerequisites.

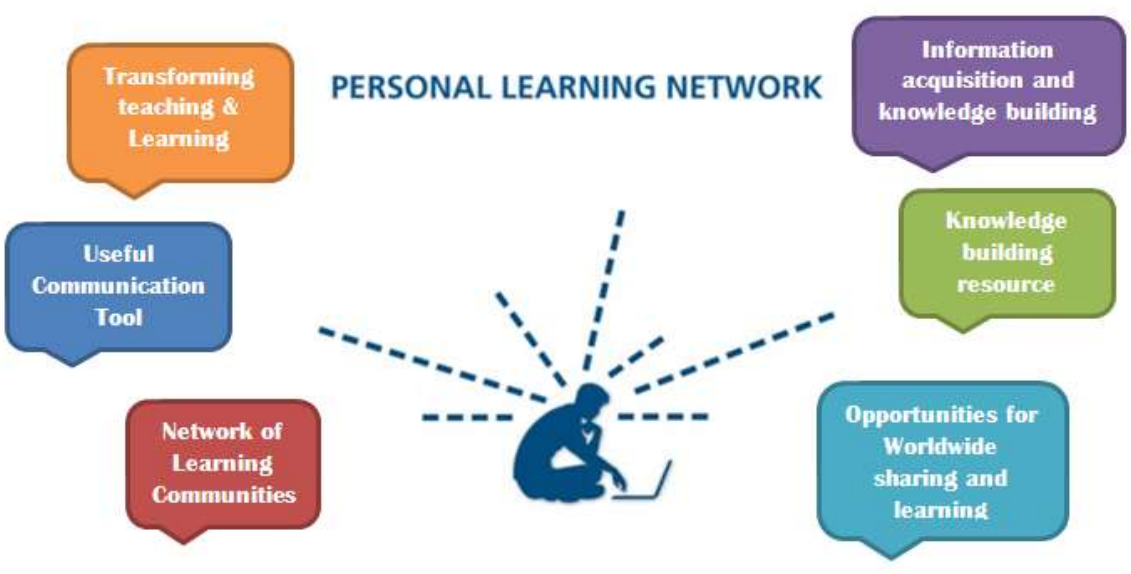

Figure 5. Personal Learning Network

TweenTribune: TweenTribune lets students stay up-to-date with current events from the Easthampton student whose tongue froze to a metal pole to a proposal by New Jersey's governor Chris Christie to lengthen the school day and the school year. It gets students in the news habit and offers a chance for them to comment on the day's events.

Twiducate: Described as a "walled garden," this site is billed as a safe site for teachers and students to collaborate. It's easily accessible and allows teachers to create a class community online using a class code rather than an email address. It also allows teachers to have total control over who is a member and what gets posted.

EDU2.0: This is for teachers looking to integrate course management systems like Blackboard, without the cost. Edu2.0 starts out by offering all its premium features on a free trial basis. At the end of the trial period, those features turn off and you can still use 
the basic platform for free. These features will be plenty for the average user, but may be enough for "power users." Edu2.0 is cloud-based and requires no significant investment in storage capacity.

Wikispaces Classroom: Collaboration is second nature to Wiki users and Wiki Classroom proves it's no exception. Wiki Classrooms are private social networks complete with news feeds and communication tools. It's safe because you decide who's invited - students, parents, administrators. You can assign, collaborate on, discuss and assess projects all within the site. It can even handle multimedia. The best part, Wikispaces Classroom is free.

Edmodo: Here's another excellent, free classroom management system. It includes news feeds, assessment tools, communication capabilities and security features.

Skype: Too many educators overlook the potential of Skype in the classrooms. It is the one site that can literally bring the outside world right into your classroom.

MinecraftEdu: The secret of MinecraftEdu is its ability to harness the power of video games to engage learners. This game allows students to collaborative, explore and problem solve all while learning about history, economics, science and math. Teachers can customize it to fit their curriculum.

Sumdog: This gaming site is kind of like flashcards on steroids. Elementary school age kids love this site. The social aspect is the ability to add friends to their accounts. Kids will race home from school to play them online. It has fun levels and clever characters.

Blackboard: This industry leader in course management systems, but it isn't something you can adopt on your own. The decision to use Blackboard is usually made at the district level, though occasionally by individual schools. Blackboard is an incredibly powerful, safe and comprehensive platform. Many newer teachers will already be familiar with it from their teacher training programs. The downside is cost. This is a very expensive platform, but you pay for quality.

\section{Interactive u-learning Model for Student Directed Learning}

Other than the teaching styles, what sets student-directed teaching apart from other teaching methods is the community of learners. Outlined by Anne Green in her book Let Them Show Us the Way: fostering independent learning in the elementary classroom, the community of learners transforms the classroom into an experiential educational space. The idea behind the interactive u-learning model for student directed learning is premised on the notion that in environment children take charge of their learning, as their strengths and gifts rise to their potential [6].

Interactive u-learning Model for Student Directed Learning is a way of arranging the classroom in which learning is actively experienced rather than passively absorbed. The children are free to move around the classroom, interacting with their peers, teacher and available resources equally and indiscriminately. This type of room configuration is meaning full for classroom discussions. This allows not only for students to gain from interaction but also interaction from the teacher. The student teacher relationship many times is based on authority. In this room figuration the teacher is seen as more interactive with the students. They are more opportunities for teacher to mentor and guide discussion and classroom instruction. This allows for the students to see the teacher as an educational model. This friendlier atmosphere will allow all students to participate in classroom discussion. The community is created in equal parts between the student and the teacher, erasing traditional hierarchies [7].

Figure 6 is the interactive u-learning model for student directed learning. The interactive learning model has different components, the learning communities, communication tools, knowledge building resource, sharing of learning resources and self-assessment. 


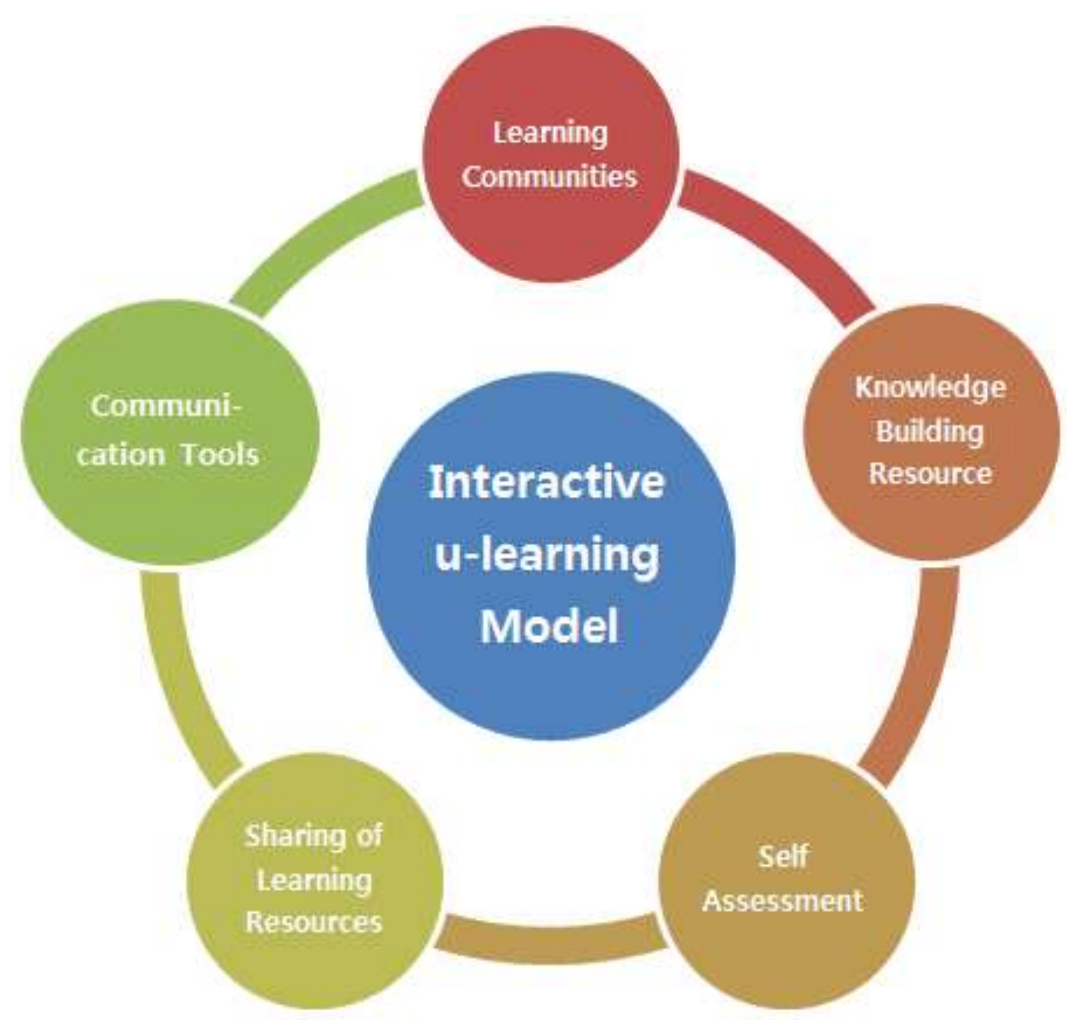

Figure 6. Interactive u-learning Model for Student Directed Learning

\section{Conclusion}

The advent of open education resources, social networking technologies, new pedagogies for online and blended learning, continuous development of ubiquitous computing technologies and its applications have brought about a revolution in the education, especially in learning environments. Although learning outside of the traditional classroom is an innovative teaching approach, the two main problems are the lack of proper learning strategies and the capacity to acquire knowledge on subjects interactively and effectively. This paper present the interactive u-learning model for students directed learning. Interactive u-learning Model for Student Directed Learning is a way of arranging the classroom in which learning is actively experienced rather than passively absorbed. The children are free to move around the classroom, interacting with their peers, teacher and available resources equally and indiscriminately. This model has different components, the learning communities, communication tools, knowledge building resource and sharing of learning resources. For the future works, includes the real implementation of the model. 
International Journal of $u-$ and $\mathrm{e}-$ Service, Science and Technology

Vol.10, No.7 (2017)

\section{References}

[1] https://www.openlearning.com/About

[2] http://mooc.org/

[3] https://blogs.cisco.com/wireless/location-based-services-in-education-enhanced-experiences-on-campus

[4] C. C. Chen and T. C. Huang, "Learning in a u-Museum: Developing a context-aware ubiquitous learning environment”, Computers \& Education, vol. 59, (2012), pp. 873-883.

[5] T. S. Ki, "Towards the Design of an Interactive U-Learning System", Journal of Security Engineering, vol. 9, no. 2, pp. 189-198.

[6] Green, Anne. Let Them Show Us the Way: fostering independent learning in the elementary classroom. Winnipeg, MN: Peguis Publishers Limited, (1995), pp. 9.

[7] Green, Anne. Let Them Show Us the Way: fostering independent learning in the elementary classroom. Winnipeg, MN: Peguis Publishers Limited, (1995), pp. 9.

[8] J. Nilles, "Some Historical Thoughts on the ee-Learning Renaissance", Innovate. Innovate Online. Retrieved 2017-06-10. 